\title{
O ENSINO DE HISTÓRIA INDÍGENA EM PROPOSTAS CURRICULARES DE ESTADOS BRASILEIROS $(2008-2016)^{*}$
}

\author{
Fernanda Pereira da Costa
}

É muito comum que, ao falarmos sobre ensino de história indígena, muitas pessoas associem à lei 11.645/2008 que tornou obrigatório, na educação básica do país, o ensino de história e cultura afro-brasileira e indígena. No entanto, a presença de temáticas relacionadas às populações indígenas nas escolas remete às origens da própria disciplina escolar, desde a primeira metade do século XIX (SILVA, 2013, p.6).

Mais do que a inserção das populações indígenas nos conteúdos a serem ensinados nas escolas do país, a principal contribuição da lei 11.645/08 é questionar quais histórias estão sendo contadas sobre as populações indígenas. Se essas histórias dão conta da presença indígena a partir da variedade étnica, social e cultural; da diversidade de contextos sociais e relações entre as populações indígenas e não indígenas; da pluralidade de ações, estratégias, resistências e negociações que permearam toda a história do que é, atualmente, o Brasil e o continente americano.

É inegável a importância da educação escolar na formação de concepções, valores e visões de mundo dos educandos. Não se trata de dizer que a escola é a única instituição que atua na formação cultural das pessoas, mas ela possui um papel relevante neste sentido. Por isso, os currículos escolares são alvo de disputas políticas e ideológicas, pois se busca, através deles, uma formação de acordo com os modelos considerados desejáveis para os grupos que possuem a predominância do poder em um determinado momento histórico (SILVA, 2012).

Durante a maior parte do tempo da História como disciplina escolar e acadêmica, as populações indígenas não foram tratadas como sujeitos históricos. Até meados do século passado, pensava-se que essas populações deveriam ser estudadas pela Etnologia e Arqueologia, o que evidencia as concepções hie-

*DOI- 10.29388/978-65-86678-50-5-0-f.129-144 
rárquicas sobre as sociedades humanas que vigoravam na História, a quem caberia o estudo das sociedades com estado e escrita, as ditas "civilizações". As populações indígenas apareciam logo no início dos livros de História do Brasil, muitas vezes descritas como selvagens e atrasadas e outras, como vítimas de um processo violento levado a cabo pelos colonizadores, mas raramente, como sujeitos que fizeram escolhas e atuaram de diversas maneiras na conformação das dinâmicas passadas.

Entendemos que os estigmas e apagamentos reforçados pelo discurso histórico têm consequências até hoje sobre como as populações indígenas são vistas pela maioria da população, o que contribui para a disseminação de preconceitos e práticas racistas contra esses povos. Adichie nos fala sobre os mecanismos de construção em relação à forma como um povo é visto:

Então é assim que se cria uma história única: mostre um povo como uma coisa, como somente uma coisa, repetidamente, e é assim que ele se tornará. É impossível falar sobre uma história única sem falar sobre poder. Há uma palavra da tribo igbo que eu lembro sempre que penso sobre as estruturas do poder no mundo, "nkali". É um substantivo que livremente se traduz: ser maior do que o outro. Como nosso mundo econômico e político, histórias também são definidas pelo princípio no nkali: como são contadas, quem as conta, quando e quantas histórias são contadas, tudo realmente depende do poder. Poder é a habilidade de não só contar a história de uma outra pessoa, mas de fazê-la a história definitiva daquela pessoa. ${ }^{1}$

Felizmente, vivemos um processo de contestação dessa história única, marcada por preconceitos e estereótipos em relação às populações indígenas. Isso tem a ver com a organização dessas populações na reivindicação de seus direitos, sendo que a própria lei 11.645/08 pode ser entendida como resultado dessas lutas, visto que era uma demanda dessas populações educar os "não indígenas” em relação à história e cultura dos povos indígenas (FANELLI, 2018, p.43 e 46).

Como parte dessa contestação e reformulação da história, é fundamental localizar, além das lutas das populações indígenas por direitos, o compartilhamento de suas vivências e pontos de vista, assim como suas histórias e culturas a partir de entrevistas, produções audiovisuais e artísticas, escrita literária e acadêmica, pesquisa e participação em eventos diversos. Para exemplificar essa

${ }^{1}$ ADICHIE, Chimamanda. Os perigos de uma história única. 2013. (9min28-10min52). Disponível em: < $\underline{\text { https: } / / \text { www.youtube.com/watch?v }=4 u X h b S W I J s}>$. Acesso em: 20.out. 2020. 
reformulação e pensar sobre suas implicações, citamos Ailton Krenak, liderança indígena que muito tem contribuído nesse processo:

O mito de origem do Brasil é aquela descoberta com as caravelas, aquela missa no monte Pascoal, é um mito de origem. Nós somos adultos, a gente não precisa ficar embalado com essa história. A gente pode buscar entender a nossa história com as diferentes matizes que ela tem e ser capaz de entender que, não teve um evento fundador do Brasil. Quando os europeus chegaram aqui, eles podiam ter todos morrido de inanição e escorbuto ou qualquer uma outra pereba nesse litoral se essa gente não tivesse acolhido eles, ensinado eles a andar aqui e dado comida pra eles, por que os caras não sabiam nem pegar um caju, não sabiam que caju era comida. E eles chegaram famélicos, doentes e Darcy Ribeiro disse que eles fediam. Quer dizer, baixou uma turma na nossa praia que estava simplesmente podre. A gente podia ter matado eles afogados. Durante muito mais do que cem anos o que os índios fizeram foi socorrer brancos flagelados chegando na nossa praia. ${ }^{2}$

A fala de Krenak nos aponta outras visões, colocando em cheque a "história única" veiculada sobre as populações indígenas, apresentando-as como ingênuas, frágeis e, facilmente dominadas pelo colonizador. Dá a essas populações agência, evidencia as suas escolhas e interesses e, em outras palavras, coloca essas populações como sujeitos históricos que eram e são. A ideia das populações indígenas como sujeitos históricos só é nova para os "não indígenas", visto que essas populações, sempre conceberam suas próprias atuações históricas (CUNHA, 1992, p.23). No momento em que essas populações ocupam o espaço político, conquistado por elas mesmas, novas narrativas emergem colocando em cheque as narrativas de origem colonial.

Neste artigo analisaremos a inserção da história e cultura indígena nas propostas curriculares de História de vinte e três Estados brasileiros e do Distrito Federal do Ensino Fundamental II e Médio, feitas, majoritariamente, a partir de 2008 até 2016, ano da proposta curricular mais recente que analisamos. O recorte temporal foi escolhido a partir da promulgação da Lei 11.645/08, que estabeleceu a obrigatoriedade do ensino de história e cultura afro-brasileira e in-

\footnotetext{
2 BOLOGNESI, Luis. Guerras do Brasil.doc. Episódio 1. Temporada 1. 2019. (7min03s 8min24s). Disponível em: <https://www.youtube.com/watch?v=VeMlSgnVDZ4\&t=13s $>$. Acesso em: 20.out. 2020.>
} 
dígena na educação básica do país ${ }^{3}$. Queremos pensar em que medida as propostas didáticas elaboradas pelos estados colaboram para formar estudantes que reconheçam as populações indígenas como sujeitos históricos que devem ser vistos sob o prisma da igualdade na diferença ${ }^{4}$, a fim de garantirmos uma educação que crie novos paradigmas de relações interculturais.

\section{As populações indígenas nas propostas curriculares de História}

$\mathrm{Na}$ análise das 24 propostas curriculares identificamos 33 temas relacionados aos povos indígenas no Brasil e na América. A discriminação dos temas pode ser observada no Quadro abaixo. Foram colocados na tabela em ordem decrescente a partir dos temas mais mencionados e discutidos na proposta de cada estado:

Quadro 1- Temas por Período e Estado

\begin{tabular}{|l|c|c|c|}
\hline \multicolumn{1}{|c|}{ Temas } & Período & Estados & Total \\
\hline 1.Indígenas e história regional & - & $\begin{array}{c}\text { RO, AP, AC, SE, PE, MS, } \\
\text { GO, DF, ES, PR e RS }\end{array}$ & 11 \\
\hline $\begin{array}{l}\text { 2.América antes dos europeus - } \\
\text { Incas, maias e astecas }\end{array}$ & Originário & $\begin{array}{c}\text { AM, AP, AC, BA, SE, DF, } \\
\text { MG, SP e PR }\end{array}$ & 9 \\
\hline 3.Pré-História nacional & Originário & $\begin{array}{c}\text { TO, RO, AP, SE, GO, DF } \\
\text { e SP }\end{array}$ & 7 \\
\hline $\begin{array}{l}\text { 4.Contato entre europeus e indí- } \\
\text { genas }\end{array}$ & Colonial & $\begin{array}{c}\text { AM, MA, AP, BA, SE, SP } \\
\text { e PR }\end{array}$ & 7 \\
\hline $\begin{array}{l}\text { 5.Sociedades indígenas antes da } \\
\text { colonização portuguesa }\end{array}$ & Originário & $\begin{array}{r}\text { BA, PE, SE, RJ, SP e RS } \\
\text { 6.Missões }\end{array}$ & 6 \\
\hline 7.População indígena no pre- & Contemporâneo & RO, SE, ES, MG, PR e RS & 6 \\
\hline
\end{tabular}

${ }^{3}$ Este artigo é um desdobramento de minha Dissertação de Mestrado em que analisei 24 propostas curriculares de estados brasileiros e do Distrito Federal. COSTA, Fernanda Pereira da. O ensino de história indígena nas propostas curriculares oficiais do Brasil ( 2008-2016). 2020. Dissertação - Escola de Filosofia, Letras e Ciências Humanas da UNIFESP. Guarulhos, 2020.

${ }^{4}$ [...] temos o direito a ser iguais quando a nossa diferença nos inferioriza; e temos o direito a ser diferentes quando a nossa igualdade nos descaracteriza. Daí a necessidade de uma igualdade que reconheça as diferenças e de uma diferença que não produza, alimente ou reproduza as desigualdades. SANTOS, Boaventura de Sousa. Reconhecer para libertar: os caminhos do cosmopolitismo multicultural. Introdução: para ampliar o cânone do reconhecimento, da diferença e da igualdade. Rio de Janeiro: Civilização Brasileira, 2003, p. 56. 


\begin{tabular}{|c|c|c|c|}
\hline sente e movimentos indígenas & & ES & \\
\hline 8.Resistência indígena & Colonial & $\begin{array}{c}\text { AM, MA, PE, BA, ES e } \\
\text { SP }\end{array}$ & 6 \\
\hline 9.Escravidão indígena & Colonial & AM, AP, MA, DF e MG & 5 \\
\hline $\begin{array}{l}\text { 10.Características gerais das et- } \\
\text { nias }\end{array}$ & Contemporâneo & SE, MS, MG e ES & 4 \\
\hline $\begin{array}{l}\text { 11.Lugar da América no imagi- } \\
\text { nário europeu }\end{array}$ & Colonial & $\mathrm{RO}, \mathrm{BA}, \mathrm{ES}$ e $\mathrm{MG}$ & 4 \\
\hline $\begin{array}{l}\text { 12.Diversidade cultural dos po- } \\
\text { vos indígenas }\end{array}$ & Contemporâneo & $\mathrm{AC}, \mathrm{DF}$ e ES & 3 \\
\hline 13.Narrativas indígenas & Contemporâneo & AP, ES e MG & 3 \\
\hline $\begin{array}{l}\text { 14.Processo de conquista e co- } \\
\text { lonização europeia nas Améri- } \\
\text { cas }\end{array}$ & Colonial & GO, MG e SP & 3 \\
\hline $\begin{array}{l}\text { 15.Guerra do Paraguai e a pre- } \\
\text { sença indígena }\end{array}$ & Independente & $\mathrm{RO}, \mathrm{MS}$ e ES & 3 \\
\hline $\begin{array}{l}\text { 16.Contribuições dos povos in- } \\
\text { dígenas na formação do Brasil }\end{array}$ & Contemporâneo & TO, MA e AL & 3 \\
\hline 17.Políticas indigenistas & Contemporâneo & $\mathrm{RO}$ e ES & 2 \\
\hline 18.Indígenas no romantismo & Independente & MG e GO & 2 \\
\hline 19.Direitos indígenas & Contemporâneo & $\mathrm{AM} \mathrm{e} \mathrm{PE}$ & 2 \\
\hline 20.Luta pela terra & Contemporâneo & $\mathrm{AM} \mathrm{e} \mathrm{DF}$ & 2 \\
\hline $\begin{array}{l}\text { 21.Nacional versus estrangeiro } \\
\text { - índios e portugueses }\end{array}$ & Colonial & ES & 1 \\
\hline $\begin{array}{l}\text { 22.Indígenas e a Constituição de } \\
1824\end{array}$ & Independente & ES & 1 \\
\hline $\begin{array}{l}\text { 23.Nações e nacionalismos- or- } \\
\text { ganizações sociopolíticas indíge- } \\
\text { nas }\end{array}$ & Independente & ES & 1 \\
\hline 24.Indígenas e gênero & Contemporâneo & ES & 1 \\
\hline $\begin{array}{l}\text { 25. Relações de trabalho nas so- } \\
\text { ciedades indígenas brasileiras e } \\
\text { americanas }\end{array}$ & Contemporâneo & ES & 1 \\
\hline 26.Guerra dos guaranis & Colonial & MG & 1 \\
\hline $\begin{array}{l}\text { 27. Estrutura social e de produ- } \\
\text { ção tupis e tapuias }\end{array}$ & Originário & MG & 1 \\
\hline $\begin{array}{l}\text { 28.Manifestações culturais de } \\
\text { origem indígena }\end{array}$ & Contemporâneo & MG & 1 \\
\hline $\begin{array}{l}\text { 29.Representação do paraíso } \\
\text { para os guaranis }\end{array}$ & Originário & $\mathrm{AM}$ & 1 \\
\hline 30.Dificuldade de sobrevivência & Contemporâneo & $\mathrm{AM}$ & 1 \\
\hline
\end{tabular}




\begin{tabular}{|l|c|c|c|}
\hline $\begin{array}{l}\text { dos povos indígenas na história } \\
\text { do Brasil }\end{array}$ & & & \\
\hline $\begin{array}{l}\text { 31.Indígenas e negros pós inde- } \\
\text { pendência dos EUA }\end{array}$ & Independente & SP & 1 \\
\hline $\begin{array}{l}\text { 32.Relações entre comunidades } \\
\text { indígenas e não indígenas }\end{array}$ & Contemporâneo & AC & 1 \\
\hline 33. Indígenas na História & Contemporâneo & PE & 1 \\
\hline
\end{tabular}

Fonte: COSTA, 2011, p.78-79.

A distribuição de temas por estado pode ser vista no Gráfico abaixo, em que apresentamos os dados de todos os estados analisados, desde o que tem o maior número de temas, Espírito Santo, até os que não trazem nenhum tema relacionado à história indígena, Mato Grosso e Piauí:

Gráfico 1 - Temas sobre história indígena/estado

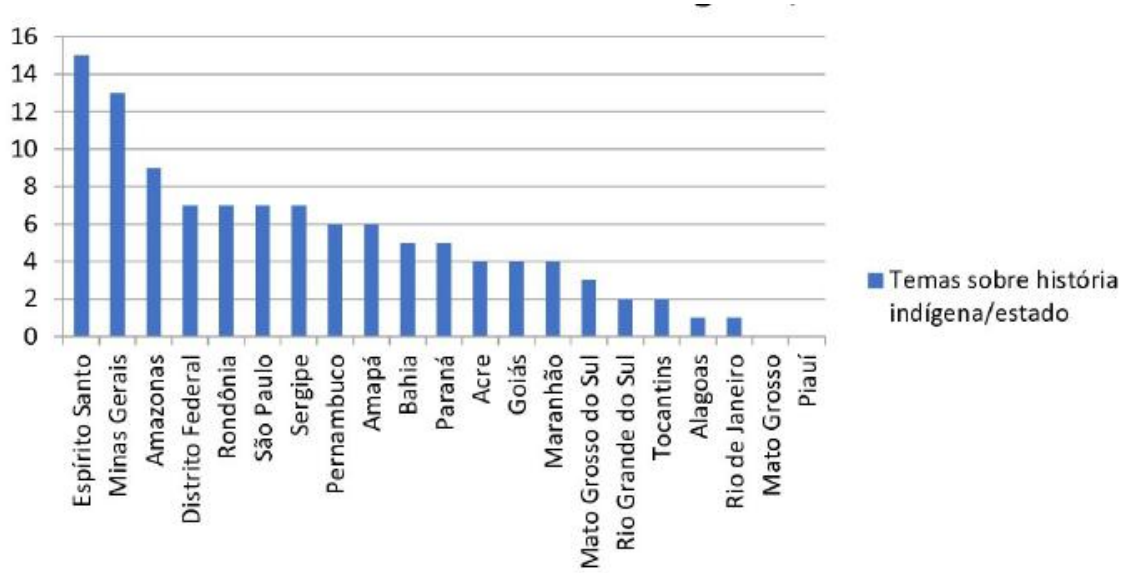

Fonte: COSTA, 2020, p.80

\section{A divisão de temas por períodos históricos}

Dividimos esses temas em quatro grandes períodos históricos: originário $^{1}$, colonial, independente (século XIX) e contemporâneo (séculos XX e

\footnotetext{
${ }^{1}$ A escolha por denominar o período como originário ocorre pela convicção de que precisamos mudar as palavras para alterar os sentidos. As denominações "pré-colombiano" ou "précolonial", que são mais utilizadas, colocam a colonização como marco principal, o que é bastante problemático do ponto de vista que partimos neste trabalho, que é o das populações indígenas como protagonistas e sujeitos históricos. Sabemos que qualquer nomenclatura possui limitações, mas optamos por este termo, pois suas limitações são menos problemáticas, em nossa concepção,
} 
XXI). A distribuição de temas ${ }^{2}$ por período pode ser observada no gráfico abaixo (Gráfico 2):

\section{Gráfico 2 - Temas de História Indígena por Período}

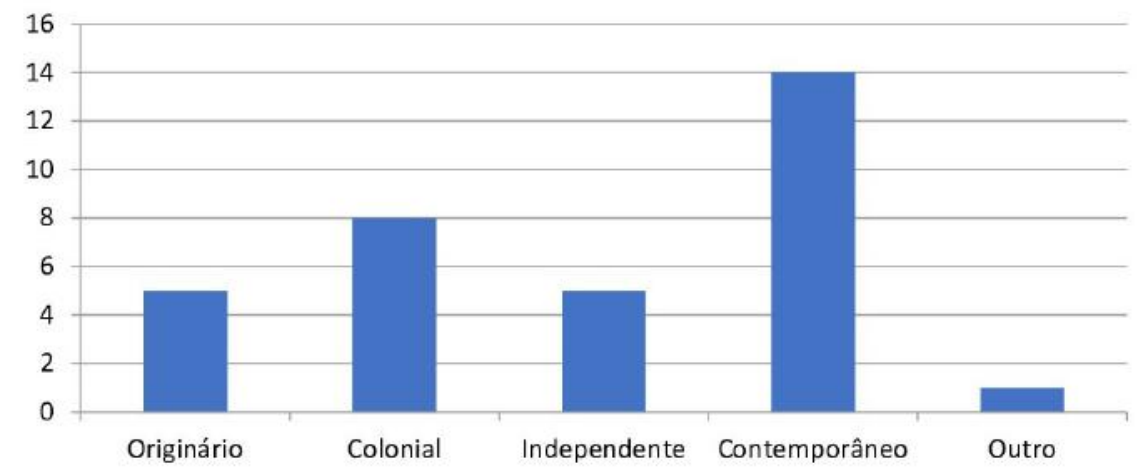

Fonte: COSTA, 2020, p. 76.

Ao identificar os temas, percebemos que havia uma recorrência de alguns currículos trazerem a história indígena vinculada à história dos estados, então, reunimos essa abordagem ao que chamamos de história regional. Enquadra-se neste tema todas as menções à história indígena que se dão no nível da história dos estados e das regiões. Achamos que seria mais interessante para a análise manter todas essas abordagens juntas em um tema que chamamos de "indígenas e a história regional". Como este tema inclui diferentes tempos históricos, ficou de fora da distribuição em períodos e, por isso, apresentamos como "Outro".

Embora o período contemporâneo apresente o maior número de temas, percebemos que é o período mais fragmentado, pois há cerca de oito temas que só aparecem em um ou dois estados. Os temas que são tratados por um maior número de estados se concentram no período originário e colonial.

do que as já citadas. Estamos nos referindo ao período em que o território, hoje denominado América, foi povoado e se tornou o espaço para o desenvolvimento de diversas culturas autóctones. São originários no sentido em que foram os primeiros povos a ocupar este território, mas reconhecemos os processos de migrações de povos da Ásia e da Australo-melanésia que resultaram nessa ocupação. A escolha acontece também porque muitos povos indígenas têm se denominado dessa forma: povos originários.

${ }^{2}$ Convém evidenciar os procedimentos do levantamento de dados para a análise. Extraímos dos documentos curriculares qualquer menção às populações indígenas do Brasil e América, independente do fato dessa menção estar nos itens identificados como conteúdo, expectativas de aprendizagem competências e habilidades ou outra nomenclatura. Essa abordagem foi escolhida para contemplar a maior quantidade de registros que envolvem história indígena. 
Entretanto, são apenas quatro temas que aparecem no período originário. Percebemos que há uma predominância de tratar das populações indígenas a partir da chegada dos europeus, ou seja, a partir do período colonial. Desta forma, é como se as populações indígenas somente adquirissem importância a partir da chegada do europeu.

Outro aspecto que notamos é o salto temporal ao tratar das populações indígenas no século XVI ou até no período originário, comparando com o período contemporâneo o que evidencia um vazio histórico, como se essas populações não estivessem presentes ao longo de toda a história. Então, são apresentadas no passado anterior à colonização ou a partir do contato com o europeu e parte-se para falar delas no presente, sendo que, uma pequena parte dos estados trata das populações indígenas no presente, apesar da pulverização de temas.

\section{Em que anos escolares a história indígena é tratada?}

Levantamos em quais anos escolares as temáticas relacionadas à história indígena se distribuíam. A partir disso, elaboramos o quadro e o gráfico a seguir:

Quadro 2 - História indígena nos anos escolares

\begin{tabular}{|c|c|c|}
\hline $\begin{array}{c}\text { Ano escolar EF II e } \\
\text { Ensino Médio) }\end{array}$ & Estados & Total \\
\hline $6^{\circ} \mathrm{EF}$ II & AM, TO, RO, AP, PE, SE, DF, PR e RS & 9 \\
\hline $7^{\circ} \mathrm{EF}$ II & AM, TO, RO, AP, PE, SE, MS, GO, DF, RJ, SP & 12 \\
\hline $8^{\circ} \mathrm{EF}$ II & e PR & 7 \\
\hline $9^{\circ} \mathrm{EF}$ II & RO, PE, SE, MS, GO, SP e PR & 5 \\
\hline $1^{\circ} \mathrm{EM}$ & RO, AC, BA, PE, SE, DF, RJ e SP & 8 \\
\hline $2^{\circ} \mathrm{EM}$ & $\mathrm{RO}, \mathrm{AP}, \mathrm{AC}, \mathrm{PE}$ e SP & 5 \\
\hline $3^{\circ} \mathrm{EM}$ & $\mathrm{AC}, \mathrm{PE}, \mathrm{DF}$ e RS & 4 \\
\hline
\end{tabular}

Fonte: COSTA, 2020, p. 80 
Gráfico 3 - Presença das temáticas indígenas distribuídas por ano e estado

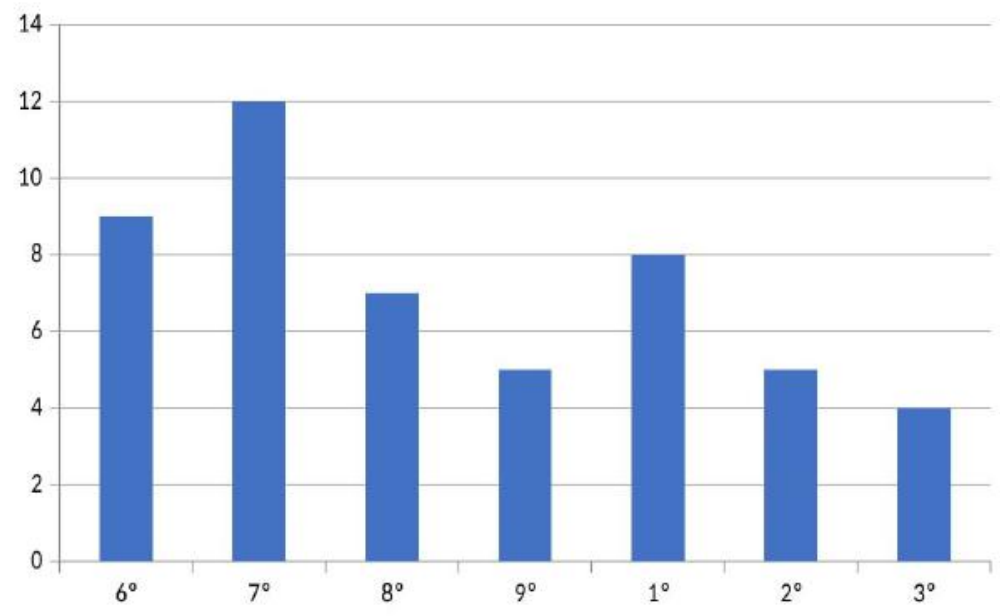

Fonte: COSTA, 2020, p. 81.

A partir desses dados, podemos inferir que o modelo predominante nos currículos de História é o baseado na divisão quadripartite de influência francesa: Idade Antiga, Idade Média, Idade Moderna e Idade Contemporânea. Dessa forma, depreendemos que a série inicial do ensino Fundamental II $\left(6^{\circ}\right.$ ano) seria responsável pela Pré-História e Idade Antiga, sendo que algumas propostas inserem as populações indígenas na Pré-História. Mas, a maior concentração de história indígena está no $7^{\circ}$ ano, em que são abordadas a Idade Média e a Idade Moderna e, fala-se das populações indígenas a partir da expansão marítima e chegada dos europeus à América. Percebemos que no $8^{\circ}$ ano o número de estados que trazem temáticas indígenas cai e, mais ainda no $9^{\circ}$ ano, que se concentra no período contemporâneo.

No Ensino Médio essa divisão temporal tende a se manter, por isso, temos o aumento de temas no $1^{\circ}$ ano, embora não chegue ao mesmo número que no $7^{\circ}$ ano, ou seja, menos estados tratam da história indígena no Ensino Médio. A partir do $2^{\circ}$ ano há uma queda e o $3^{\circ}$ é o ano com a menor presença de temáticas indígenas.

\section{A história indígena em relação aos demais conteúdos}

Para termos referenciais de comparação sobre a expressão da história indígena nas propostas curriculares, foi necessário fazer um levantamento e ca- 
tegorização do total de conteúdos prescritos pelos documentos. Como nosso objeto de pesquisa está incluído no que denominamos História do Brasil e da América, levantamos essas categorias e, também, o que chamamos de História Geral, que seriam os conteúdos que envolvem história da Europa, África e Ásia. Abaixo, segue um quadro (Quadro 3) com a distribuição desses conteúdos por área assim como o total:

Quadro 3 - Conteúdos por estado

\begin{tabular}{|c|c|c|c|c|}
\hline Estado & $\begin{array}{c}\text { História do } \\
\text { Brasil }\end{array}$ & $\begin{array}{c}\text { História da } \\
\text { América }\end{array}$ & História Geral & Total \\
\hline Minas Gerais & 143 & 24 & 102 & 269 \\
\hline Espírito Santo & 118 & 13 & 199 & 330 \\
\hline Distrito Federal & 58 & 10 & 102 & 170 \\
\hline Sergipe & 150 & 20 & 130 & 300 \\
\hline Rondônia & 93 & 8 & 79 & 180 \\
\hline São Paulo & 46 & 22 & 228 & 296 \\
\hline Amapá & 123 & 16 & 131 & 270 \\
\hline Bahia & 24 & 4 & 63 & 91 \\
\hline Acre & 61 & 16 & 89 & 166 \\
\hline Pernambuco & 51 & 4 & 106 & 161 \\
\hline Mato G. do Sul & 22 & 3 & 47 & 72 \\
\hline Goiás & 83 & 14 & 172 & 269 \\
\hline Paraná & 51 & 8 & 62 & 121 \\
\hline Amazonas & 182 & 38 & 160 & 380 \\
\hline Tocantins & 22 & 5 & 56 & 83 \\
\hline Rio G. do Sul & 14 & 6 & 26 & 46 \\
\hline Alagoas & 5 & 0 & 12 & 17 \\
\hline Mato Grosso & 6 & 0 & 36 & 42 \\
\hline Rio de Janeiro & 33 & 15 & 106 & 154 \\
\hline Maranhão & 12 & 3 & 27 & 42 \\
\hline Ceará & - & - & - & - \\
\hline Piauí & 1 & - & 22 & 23 \\
\hline Santa Catarina & - & & - & - \\
\hline
\end{tabular}

Fonte: COSTA, 2020, p.82-83.

A partir deste levantamento fizemos um comparativo da proporção da história indígena em relação ao total de conteúdos. Isso foi muito relevante, pois os Estados que mais trazem temas sobre história indígena, como Espírito Santo e Minas Gerais não são os que mais abordam a história indígena, como 
podemos observar no quadro abaixo (Gráfico 3):

Gráfico 4 - História indígena (\%)

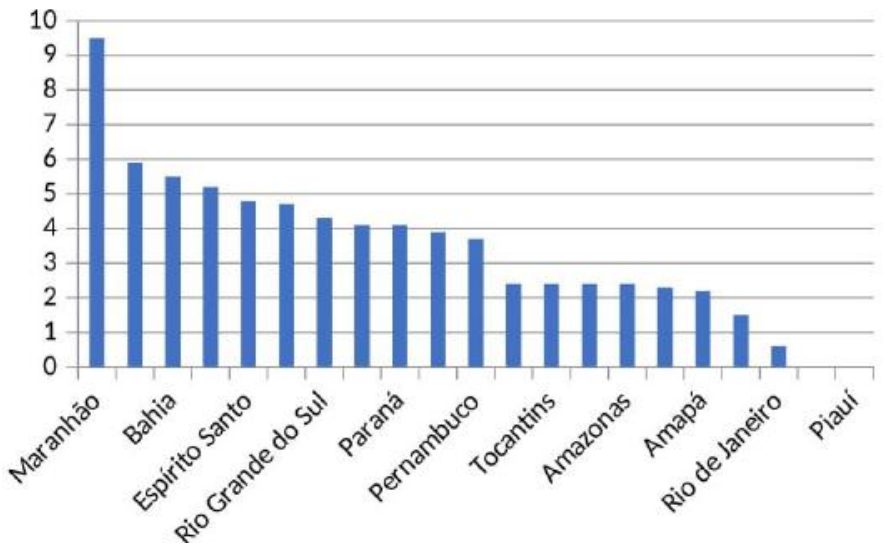

História indigena (\%)

Fonte: COSTA, 2020, p.85

Os conteúdos que envolvem história e cultura indígena não chegam a $10 \%$ em nenhuma proposta curricular em relação ao total de conteúdos prescritos. A proposta com o maior índice de presença é a do Maranhão, com 9,5\% de conteúdos que envolve história indígena. A ampla maioria das propostas traz menos de $5 \%$ dos conteúdos relacionados à história indígena, e as propostas do Piauí e Mato Grosso são as únicas, das que apresentam conteúdos, a não prescreverem nenhum tema relacionado à história e cultura indígena.

É possível afirmarmos que apenas nos currículos de Minas Gerais e Rondônia temos um pequeno predomínio de prescrição de conteúdos relacionados à História do Brasil, enquanto o de Sergipe possui metade dos conteúdos. Mais da metade das propostas curriculares (12 propostas) ficam entre $20 \mathrm{a}$ $40 \%$ dos conteúdos relacionados à História do Brasil.

Por outro lado, mais da metade dos currículos (13 propostas curriculares) possuem $60 \%$ ou mais de seus conteúdos relacionados à História Geral, sendo a proposta do Piauí a que mais possui temáticas relacionadas à História geral, chegando a $96 \%$ dos conteúdos apresentados. Convém ressaltar que, nessa área, os conteúdos predominantes são relacionados à história da Europa.

Sobre os conteúdos que envolvem História da América, verificamos que a proposta que mais apresenta temas nessa área é a do Rio Grande do Sul, com 13\% dos conteúdos relacionados. Mais da metade das propostas (12) pos- 
sui entre 5\% a 10\% de conteúdos relacionados à História da América, e é também a área em que mais propostas não abordam nenhum conteúdo, como é o caso de Alagoas, Mato Grosso e Piaú́.

Podemos afirmar, a partir dos dados apresentados, que a maioria das propostas curriculares prioriza conteúdos relacionados à História Geral, com ênfase em história do continente europeu. Algumas propostas se destacam por um ligeiro predomínio de História do Brasil, como Minas Gerais e Rondônia, sendo que essas duas propostas, a do Amazonas e Sergipe são as únicas em que a História do Brasil somada à História da América representa mais da metade dos conteúdos. Nas demais, o predomínio de História Geral é amplo.

Entendemos que esses dados não são apenas números, são escolhas políticas. As propostas curriculares são construtos sociais, marcados por interesses e que buscam atingir finalidades específicas (SILVA, 2012). Logo, os conteúdos prescritos pelas propostas analisadas priorizam determinados conhecimentos e expressam, assim, o que consideram mais relevante para ser ensinado.

\section{Comentários sobre temas e abordagens relevantes}

A partir dos dados apresentados, consideramos que o espaço dado à história indígena ainda é muito pequeno nas propostas curriculares brasileiras. Não caberá, a este artigo, uma análise pormenorizada das temáticas que envolvem a história indígena ${ }^{3}$, porém, gostaríamos de salientar a abordagem de algumas propostas que se mostram interessantes no sentido em que se aproximam de tratar as populações indígenas como sujeitos históricos. Neste sentido, destacamos o tema que aborda as "narrativas indígenas", presente nas propostas de Amapá, Minas Gerais e Espírito Santo, porém, ressaltamos a necessidade de reconhecer as historicidades dessas narrativas. Também evidenciamos o tema que apresenta as "organizações sócio-políticas indígenas" em comparação a outros tipos de organizações sócio-políticas, presente na proposta do Espírito Santo, além do tema "visão do paraíso para os guaranis", que traz a perspectiva de "paraíso" para os guaranis de forma comparativa a outros grupos, presente na proposta do Amazonas.

Entendemos que essas abordagens comparativas são muito interessantes na medida em que evidenciam a diversidade de perspectivas e organizações e colocam as populações indígenas no lugar histórico e de importância que qualquer povo deve possuir. Ou seja, qualquer povo deve ser visto em sua com-

\footnotetext{
${ }^{3}$ Uma análise detalhada dos temas por período foi feita na dissertação de mestrado já referida.
} 
plexidade, história, visões de mundo, valores civilizatórios, organizações sociais e políticas; não apenas os gregos, romanos, portugueses, franceses, etc.

Cabe ainda mencionar o tema da escravidão no Brasil. Trata-se de um tema muito frequente no ensino de História, estando em 16 das 23 propostas curriculares analisadas. Entretanto, a escravidão que mais aparece é a escravidão africana, que envolve discussões sobre o tráfico negreiro, a diáspora negra e o papel dos negros escravizados na produção colonial. Apenas cinco estados tratam da escravidão das populações indígenas. São eles: Amazonas, Amapá, Maranhão, Distrito Federal e Minas Gerais. Essa abordagem minoritária dialoga com a abordagem historiográfica hegemônica em que a formação brasileira es taria relacionada à escravidão africana e, para que essa explicação tenha se constituído de forma hegemônica, foi necessário marginalizar a escravidão indígena. Essa abordagem tem sido questionada pelas pesquisas da nova história indígena que tem se debruçado sobre as diversas formas de escravidão indígena, seja pela guerra justa, por resgate ou apresamentos dessas populações ${ }^{4}$.

A proposta do Amazonas fica em terceiro lugar das que mais apresentam temas relacionados às populações indígenas, apresentando nove temas. Apesar de algumas abordagens problemáticas, como tratar das populações indígenas somente a partir do contato com o europeu, ignorando a história pregressa, a proposta reconhece a escravidão indígena, algo que aparece em apenas cinco propostas, além de evidenciar a situação atual em que as populações indígenas lutam pela terra e pela garantia de direitos, algo abordado por um número ainda mais reduzido de currículos.

A proposta do Distrito Federal é a quarta a apresentar mais temas relacionados à história indígena, entretanto, estes temas concentram-se nos períodos originário e contemporâneo, o que contribui para ideia de um vazio histórico em que as populações indígenas são tratadas antes do contato com o europeu e no presente. Distintivamente, a proposta do Espírito Santo é a que possui as temáticas distribuídas de maneira mais regular, estando as populações indígenas presentes em todos os períodos históricos. Também é a que possui mais temas relacionados à história indígena, sendo 15 no total, alguns deles apenas presentes nessa proposta como "indígenas e gênero" e "indígenas e a Constituição de 1824".

Vale ainda evidenciar as propostas de Minas Gerais e Bahia que se des-

\footnotetext{
4 A pesquisadora e professora do Instituto de Filosofia e Ciências Humanas (IFCH) da Universidade Estadual de Campinas (UNICAMP) Camila Loureiro Dias, apresentou em aula no curso Introdução à história indigena, promovido pelo CEMA-USP, resultados de sua pesquisa de pósdoutorado que se debruça sobre trabalho livre e escravo no Maranhão e Grão Pará entre os séculos XVII e XVIII.
} 
tacam pela representatividade de temas relacionados às questões indígenas. No caso de Minas Gerais, a proposta apresenta 13 temas que envolvem as temáticas indígenas, distribuídas de maneira mais regular e tendo alguns temas que somente aparecem nela como "guerras dos guaranis" e as "manifestações culturais de origem indígena". A proposta da Bahia traz cinco temáticas, o que representa $5,5 \%$ do total de temas, embora estejam restritos ao período originário e colonial, o que colabora com a invisibilidade das populações indígenas no presente.

\section{Considerações finais}

De maneira geral, observamos que a história e o ensino de História tendem a se centrar em sociedades que possuem organizações estatais e valorizam aspectos como escrita, monumentalidade e hierarquias sociais. Apesar de todos os avanços e críticas, ainda temos muitas dificuldades em estudar as sociedades que recusam o estado como organização política e que não tem na monumentalidade e na escrita, traços fundamentais de suas organizações sociais. Trata-se de sociedades que não possuem estado não por uma incapacidade ou por estarem em estágios primitivos de desenvolvimento; mas sim por o rejeitarem, por ele não ser um atributo desejado por esses grupos, conforme defendeu Clastres (1979).

A centralidade de sociedades estatais é percebida nas propostas curriculares, por exemplo, no tratamento que é dispensado às sociedades incas, maias e astecas, que são vistas como "civilizações" em contraposição aos "povos indígenas do Brasil". Os primeiros também são tratados de maneira histórica, fato que implica pensar suas ações e transformações ao longo do tempo, o que aparece de forma muito incipiente para os povos indígenas do Brasil.

Dessa forma, consideramos que um dos problemas para o estudo e ensino de história indígena é a permanência de um modelo que privilegia sociedades com estado e, muitas vezes, com escrita, em detrimento a sociedades que possuem organizações sociais que não possuem estado, não por uma incapacidade, mas por uma escolha. Mesmo que o discurso não seja mais o do século XIX, discurso no qual as sociedades indígenas do Brasil eram vistas como sociedades sem história, na prática ainda temos um tratamento histórico para determinadas populações, enquanto outras são excluídas dessa perspectiva.

A história indígena coloca diversos desafios para a pesquisa, isso porque exige de nós, historiadores, metodologias que podem envolver o trabalho 
interdisciplinar com a Arqueologia e Antropologia. No entanto, temos um número crescente de historiadores produzindo pesquisas nessa área, fato que tem contribuído com a perspectiva de resgatar a historicidade e a agência das populações indígenas. Nesse sentido, as palavras de Monteiro (1999, p.247) ainda são atuais:

\begin{abstract}
Reconstruir a história para construir o futuro é algo que está, sem dúvida, na agenda de uma parte expressiva do movimento indígena atual, porém, é uma tarefa que exige uma reconfiguração radical das noções ainda prevalecentes na história que se ensina hoje. Assim, o caminho pela frente ainda é longo, até porque, voltando para a citação no início deste texto, o caminho para o passado também está cheio de obstáculos.
\end{abstract}

O processo de "reconstruir a história" busca fazer emergir narrativas que foram desconsideradas ao longo dela. É, assim, para além de um resgate da existência plena dos povos indígenas, a convicção de que a invisibilidade desses povos torna inviável a compreensão de processos históricos nos quais foram sujeitos e agiram, juntamente a outros sujeitos, conformando as dinâmicas passadas. Resgatar os lugares complexos, múltiplos e, por vezes, contraditórios que as diversas populações indígenas ocuparam ao longo da História é, também, um resgate de humanidade e uma via necessária na luta contra o silenciamento, a inferiorização e o racismo que marcaram o percurso dessas populações desde o período colonial. Essa luta é resultado da articulação dos povos indígenas pelo seu direito histórico de existir e nos coloca diante da necessidade de decolonizar as mentes, as práticas sociais e os saberes.

Não há ensino de História que contemple a agência plena das populações indígenas se não estiver comprometido com o combate ao racismo, com a superação de hierarquias e desigualdades que colocam "os brancos e branqueados acima dos negros e indígenas" (WALSH, 2001), servindo aos interesses da acumulação de capital. São disputas por modelos de sociedade e, também, de ensino que estão em pauta, e não apenas a inserção das temáticas indígenas nas propostas curriculares e na escola. A boa notícia é que esse processo já se iniciou, embora haja um longo caminho pela frente.

\title{
Referências
}

CUNHA, Manuela Carneiro da (org.). História dos Índios no Brasil. São Paulo: Companhia das Letras, 1992, p. 23. 
CLASTRES, Pierre. A sociedade contra o estado (investigações de Antropologia política). Edições Afrontamento: Porto, 1979.

COSTA, Fernanda Pereira da. O ensino de história indígena nas propostas curriculares oficiais do Brasil (2008-2016). 2020. Dissertação (Mestrado)Escola de Filosofia, Letras e Ciências Humanas da UNIFESP, Guarulhos, 2020.

FANELLI, Giovana de Cássia Ramos. A lei 11.645/08: história, movimentos sociais e mudança curricular. Dissertação (Mestrado) - Faculdade de Educação da Pontifícia Universidade Católica, São Paulo, 2018.

MONTEIRO, John Manuel. "Armas e armadilhas: História e resistência dos índios". In: Adauto Novaes (org.). A outra margem do Ocidente. São Paulo, Companhia das Letras, 1999.

SANTOS, Boaventura de Sousa. Reconhecer para libertar: os caminhos do cosmopolitanismo multicultural. Rio de Janeiro: Civilização Brasileira, 2003.

SILVA, Adriane Costa da. Versões didáticas da história indígena (18791950). 2013. 153 f. Dissertação (Mestrado) - Faculdade de Educação da Universidade de São Paulo, São Paulo, 2013.

SILVA, T.T. da. "A produção social da identidade e da diferença". In: SILVA, T.T da (org.). Identidade e diferença: a perspectiva dos estudos culturais. Petrópolis, RJ: Vozes, 2012. p.73-102.

WALSH, Catherine. La educación intercultural en la educación. Peru: Ministério de Educacion, 2001, p.4. Tradução própria.

\section{Vídeos}

ADICHIE, Chimamanda. Os perigos de uma história única. 2013. $9 \min 28$ 10min52. Disponível em: <https://www.youtube.com/watch? $\mathrm{v}=4 \mathrm{uXhbSWIJs}>$. Acesso em: 30 out. 2020.

BOLOGNESI, Luis. Guerras do Brasil.doc. Episódio 1. Temporada 1. 2019. $7 \min 03 \mathrm{~s}-8 \min 24 \mathrm{~s}$. Disponível em: < https://www.youtube.com/watch? $\mathrm{v}=\mathrm{VeMlSgnVDZ4 \& t=13 \textrm {s }}>$. Acesso em: 30 out. 2020. 